\title{
Survival and reoperation pattern after 20 years of experience with aortic valve-sparing root replacement in patients with tricuspid and bicuspid valves
}

\author{
Stefan Klotz, MD, Sina Stock, MD, Hans-Hinrich Sievers, MD, Michael Diwoky, Michael Petersen, MD, \\ Ulrich Stierle, MD, and Doreen Richardt, MD
}

\section{ABSTRACT}

Objective: Remodeling or reimplantation are established operative techniques of aortic valve-sparing root replacement. Long-term follow-up is necessary comparing tricuspid and bicuspid aortic valves.

Methods: A total of 315 patients (tricuspid, $\mathrm{n}=225$, bicuspid, $\mathrm{n}=89$, quadricuspid, $\mathrm{n}=1$; remodeling, $\mathrm{n}=101$, reimplantation, $\mathrm{n}=214$ ) were evaluated. Mean follow-up was $10.1 \pm 5.6$ and $6.4 \pm 4.2$ years for the remodeling and reimplantation group, respectively. Longest follow-up was 21.9 years with $99.2 \%$ completeness. Mean age of the patients was $55.9 \pm 14.3$ for the remodeling group and $48.9 \pm 14.5$ years for the reimplantation group.

Results: There was no significant difference in survival between the remodeling and reimplantation group $(P=.11)$. Survival was comparable with the normal population in the reimplantation group $(P=.33)$. Risk factors for late death were age, diabetes, and a greater New York Heart Association classification. Cumulative incidence of reoperation at 10 years was $5.8 \%$ for the reimplantation and $11.7 \%$ for the remodeling group $(P=.65)$. Overall, there was no difference in the cumulative incidence of reoperation between tricuspid and bicuspid aortic valve patients $(P=.13)$; however, a landmark analysis showed that in the second decade, the cumulative incidence of reoperation was greater in bicuspid aortic valve patients $(P<.001)$. A total of 10 of 11 reoperated bicuspid aortic valves were degenerated.

Conclusions: The remodeling and reimplantation aortic valve-sparing root replacement techniques provided excellent long-term survival. Although the number of patients was relatively small, we provide some hints that in the second decade after the operation, especially in bicuspid aortic valve patients, the risk of reoperation may be increased, needing further evaluation. (J Thorac Cardiovasc Surg 2018;155:1403-11)

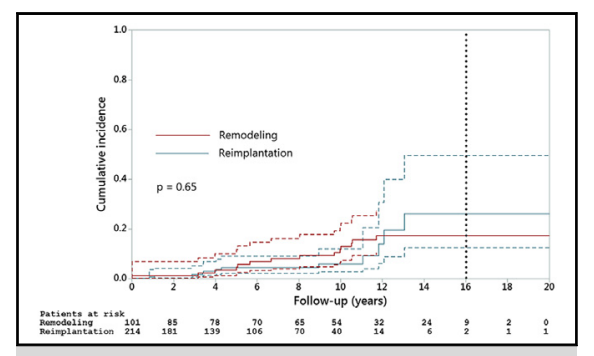

Cumulative incidence of reoperation after aortic valve-sparing root replacement.

\section{Central Message}

Aortic valve-sparing root replacement offers near-normal survival. However, the risk of reoperation is increased in the second postoperative decade, especially in patients with a bicuspid valve.

\section{Perspective}

Aortic valve-sparing root replacement techniques are appealing options to treat aortic root dilatation with or without aortic valve disease. Data of other groups regarding reoperation in the second decade after the operation in patients with a bicuspid aortic valve are required to obtain further insight in the probably more complex issue of bicuspid aortic valve and surgical treatment.

See Editorial Commentary page 1412.
In patients with aortic root aneurysm and macroscopic intact aortic valve leaflets, a valve-sparing root replacement may be indicated to prevent the shortcomings of replacement substitutes such as bioprostheses and mechanical valves. Such

\footnotetext{
From the Department of Cardiac and Thoracic Vascular Surgery, University Medical Center Schleswig-Holstein, Campus Lübeck, Lübeck, Germany.

Drs Klotz and Stock contributed equally to this article.

Received for publication July 5, 2017; revisions received Nov 15, 2017; accepted for publication Dec 5, 2017; available ahead of print Jan 17, 2018.

Address for reprints: Hans-Hinrich Sievers, MD, Department of Cardiac and Thoracic Vascular Surgery, University Medical Center Schleswig-Holstein, Ratzeburger Allee 160, Luebeck 23538, Germany (E-mail: Hans-Hinrich.Sievers@uksh.de). $0022-5223 / \$ 36.00$

Copyright (C) 2017 by The American Association for Thoracic Surgery https://doi.org/10.1016/j.jtcvs.2017.12.039
}

repair operations are performed via 2 different techniques: remodeling (Yacoub) ${ }^{1}$ and reimplantation (David). ${ }^{2}$ Both are appealing aortic valve reconstructions warranting excellent hemodynamics, a low incidence of thromboembolism, and a low incidence of bleeding complications without the need for anticoagulation. The remodeling technique more physiologically preserves the aortic root distensibility and

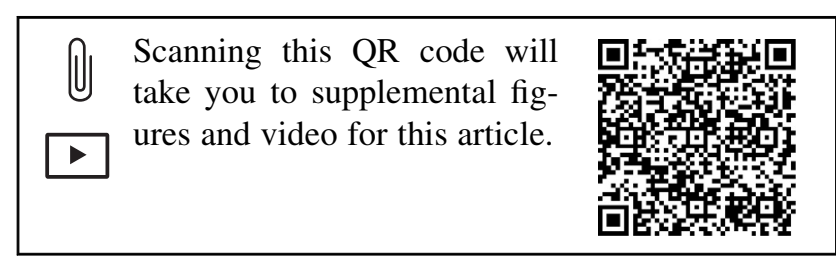




\section{Abbreviations and Acronyms \\ $\mathrm{BAV}=$ bicuspid aortic valve \\ $\mathrm{CI}=$ confidence interval \\ $\mathrm{CTD}=$ connective tissue disease \\ $\mathrm{HR}=$ hazard ratio \\ $\mathrm{TAV}=$ tricuspid aortic valve}

movement of the aortic cusps. ${ }^{3,4}$ The clinical relevance of it, however, is unclear and may surface after only decades. Midterm results after both valve-sparing techniques have been reported to be excellent. ${ }^{5-9}$ For further judgment of this surgical principle, however, results of long-term, preferably life-long follow-up, are essential. ${ }^{10}$ Because survival and reoperation are the most relevant determinants for treatment quality, we present survival and reoperation patterns in patients after aortic valve-sparing root replacement, comparing the remodeling and reimplantation technique including the bicuspid aortic valve (BAV) and tricuspid aortic valve (TAV).

\section{MATERIALS AND METHODS}

From March 1994 to December 2016, 434 patients were consecutively operated on with the valve-sparing root replacement technique. After exclusion of patients with acute type A dissection, 315 patients $(240$ male, $51.1 \pm 14.8$ years, mean follow-up: $7.5 \pm 5.0$ years, reverse Kaplan-Meier method: median follow-up $=7.9$ years $(95 \%$ confidence interval [CI], 7.6-8.2 years), 2377.99 patient*years) were left for the study. The remodeling technique was performed in 101 patients; the reimplantation technique (Video 1) in 214 patients. A histogram with the annual number of the 2 procedures is depicted in Figure E1.

After approval by the ethical committee, patients' consent was obtained. Follow-up data were obtained between 2015 and 2017 via written questionnaires to the patients or their family doctors and via outpatient visits. The longest follow-up was 21.9 years, and the follow-up completeness-calculated according Clark and colleagues ${ }^{11}$ - was $99.2 \%$. Preoperative data are presented in Table 1. The choice for either of the 2 techniques in the early days of valve-sparing surgery was related to the surgeon's preference, not to the dimensions of the annulus or other pathologies. Only if the annulus appeared enlarged ( $>28-30 \mathrm{~mm})$, a David annuloplasty ${ }^{12}$ was performed in the remodeling group $(n=16)$. When we evaluated our results in 2008 , we found that best hemodynamic results were obtained with the remodeling technique at lower annulus diameters and vice versa with the reimplantation technique. ${ }^{13}$ Since then, we have used both the techniques according to the annulus diameter.

In patients with an annulus diameter of 28 to $30 \mathrm{~mm}$, the remodeling technique was applied, and in those with an annulus diameter $>30 \mathrm{~mm}$, the reimplantation technique was applied. Our operative technique has been reported in detail previously. ${ }^{3}$ Only leaflets that had a normal or near-normal macroscopic appearance with good pliability were accepted for repair. Additional cusp intervention was performed in 137 patients (Table 2). A central leaflet stich was performed after root replacement in both remodeling and reimplantation. By this technique, the absolute parallelism of the leaflets with respect to the normal-appearing reference leaflet was judged and if additional length, which means some kind of prolapse, was present, this amount of additional length was centrally plicated with 6/0 U-stitches. In some cases, the thickened raphe of BAV type 1 left-right was resected and replaced with a triangular autologous glutaraldehyde preserved pericardial patch with $6 / 0$ running suture.

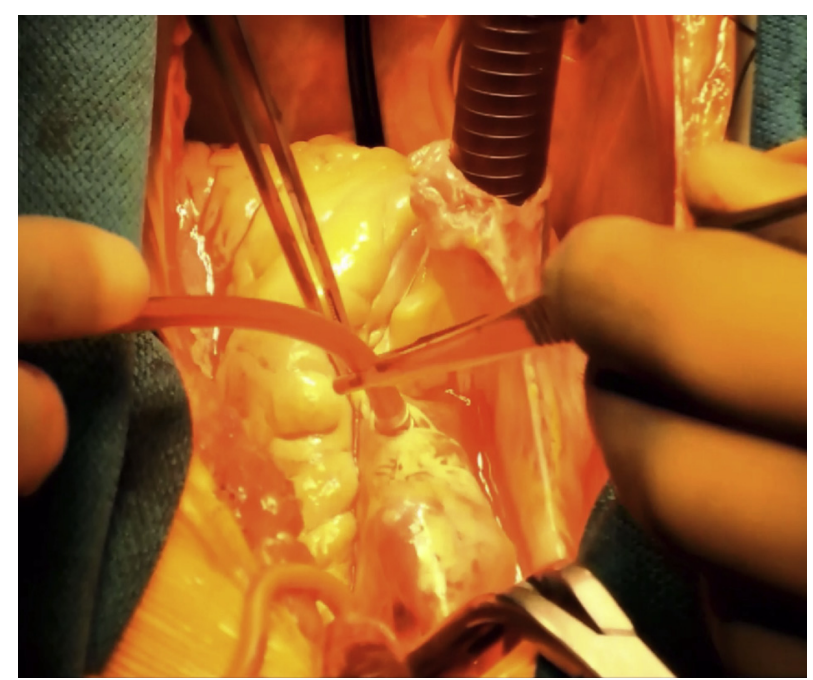

VIDEO 1. Shown is a David reimplantation operation with a sinus prosthesis. In detail: transection of the aorta $1 \mathrm{~cm}$ above commissures, commissural suture $2 / 0$ multifilament with pledget, dissection of sinus, sinus excision (noncoronary), left-coronary button preparation, preparation between aortic root and right ventricular outflow tract, sizing of the graft, preparing the sinus prosthesis, subannular implantation with multiple 2/ 0 multifilament Teflon pledget watertight U-stitches, knotting over Hegar dilator 24 or 26 (related to body surface area), commissure resuspension on the prosthesis with Teflon pledgets outside, sinus suture from inside the graft with 5/0 Prolene, knotting sinus suture over Teflon felt of commissure, left-coronary and right-coronary artery button anastomoses, central leaflet stitch for evaluating parallelism of the free edge of the leaflets, retracted right leaflet extension with glutaraldehyde prepared autologous pericardium, central plication of left coronary leaflet, postoperative 3dimensional echocardiogram showing 3 sinuses, plication left leaflet and cusp extension of right leaflet, longitudinal echocardiogram showing central trace aortic insufficiency. Video available at: http://www.jtcvsonline.org/ article/S0022-5223(17)32847-7/fulltext.

Intraoperative or predischarge echocardiography revealed aortic insufficiency of grade none/trace in 287 patients (none, $\mathrm{n}=230$; trace, $\mathrm{n}=57$ ), mild in 20 patients, mild to moderate in 1 patient, and unknown in 7 patients.

\section{Statistical Analysis}

For statistical analysis, the $\chi^{2}$ test, Fisher exact test, the Mann-Whitney $U$ test, and the Student $t$ test were used where appropriate. Nominal and ordinal data are presented as absolute numbers and relative frequencies and continuous data as mean with standard deviations. Standardized differences were calculated via the definition recommended by Austin. ${ }^{14}$ The method of Benjamini and Hochberg ${ }^{15}$ was used to control the false discovery rate, resulting in a corrected significance level of .008. Calculations were performed with IBM SPSS Statistics (IBM Corp. Released 2013. IBM SPSS Statistics for Windows, Version 22.0; IBM Corp, Armonk, NY) and SAS software (Version 9.4; SAS Institute Inc, Cary, NC).

Patient survival rates were analyzed by the Kaplan-Meier method and the log-rank test and reoperation by the cumulative incidence function adjusting reoperation for the competing risk of death and Gray's log-rank test. For patients living longer than 10 years, the reoperation rates in the remodeling and in the reimplantation group were calculated by the landmark analysis that is competing risk analysis, considering only patients with the occurrence with reoperation or death conditional on neither having occurred in the first 10 years. The Cox proportional hazards model was used to compare survival 
TABLE 1. Perioperative characteristics of the patient population

\begin{tabular}{|c|c|c|c|c|}
\hline Parameter & Reimplantation $(n=214)$ & Remodeling $(n=101)$ & Standardized difference & $P$ value \\
\hline Male sex & $179(83.6)$ & $61(60.4)$ & 53.6 & $<.001$ \\
\hline Age, y & $48.9 \pm 14.5$ & $55.9 \pm 14.3$ & -48.3 & $<.001$ \\
\hline Bicuspid aortic valve & $67(31.3)$ & $22(21.8)$ & 22.0 & .082 \\
\hline Type 0 & $11(5.1)$ & $4(4.0)$ & & \\
\hline Type 1 & $52(24.3)$ & $15(14.9)$ & & \\
\hline Type 2 & $2(0.9)$ & 0 & & \\
\hline Unknown & $2(0.9)$ & $3(3.0)$ & & \\
\hline Diabetes mellitus & $6(2.8)$ & $5(5.0)$ & -11.1 & .339 \\
\hline Hypertension & $135(63.1)$ & $70(69.3)$ & -13.2 & .312 \\
\hline Renal disease & $2(0.9)$ & $1(1.0)$ & -0.6 & 1 \\
\hline $\begin{array}{l}\text { Serum creatinine, } \mu \mathrm{mol} / \mathrm{L} \\
\text { Unknown }\end{array}$ & $\begin{array}{c}83.5 \pm 23.3 \\
2\end{array}$ & $\begin{array}{c}84.0 \pm 27.8 \\
6\end{array}$ & -1.9 & .667 \\
\hline Previous cardiac surgery & $9(4.2)$ & $2(2.0)$ & 12.9 & .513 \\
\hline Coronary artery disease & $27(12.6)$ & $19(18.8)$ & -17.1 & .172 \\
\hline Peripheral artery disease & $2(0.9)$ & $2(2.0)$ & -8.7 & .596 \\
\hline Cerebrovascular disease & $8(3.7)$ & $7(6.9)$ & -14.2 & .258 \\
\hline Hyperlipidemia & $56(26.2)$ & $30(29.7)$ & -7.9 & .588 \\
\hline Chronic pulmonary disease & $10(4.7)$ & $3(3.0)$ & 8.9 & .561 \\
\hline CTD & 35 (16.4) & 12 (11.9) & 12.9 & .397 \\
\hline Marfan & $33(15.4)$ & $12(11.9)$ & & \\
\hline Loeys-Dietz & $2(0.9)$ & 0 & & \\
\hline Mitral valve insufficiency $\geq$ grade I & $43(20.1)$ & $28(27.7)$ & -18.0 & .149 \\
\hline Aortic valve insufficiency & & & 1.9 & .084 \\
\hline None/trace & $27(12.6)$ & 13 (12.9) & & \\
\hline Mild & $28(13.1)$ & $18(17.8)$ & & \\
\hline Moderate & $66(30.8)$ & $36(35.6)$ & & \\
\hline Severe & $93(43.5)$ & $31(30.7)$ & & \\
\hline Unknown & 0 & $3(3)$ & & \\
\hline Annulus diameter, $\mathrm{mm}$ & $31.9 \pm 5.2$ & $31.4 \pm 7.5$ & 7.6 & .739 \\
\hline Unknown & 86 & 72 & & \\
\hline Sinus diameter, $\mathrm{mm}$ & $49.6 \pm 9.6$ & $51.7 \pm 11.2$ & -20.3 & .200 \\
\hline Unknown & 42 & 43 & & \\
\hline STJ diameter, $\mathrm{mm}$ & $41 \pm 6.6$ & $40.8 \pm 8$ & 2.1 & .939 \\
\hline Unknown & 95 & 82 & & \\
\hline Ascending aorta diameter, $\mathrm{mm}$ & $50.2 \pm 12.4$ & $56.3 \pm 12.3$ & -49.9 & $<.001$ \\
\hline Unknown & 48 & 18 & & \\
\hline LVEF & & & 8.8 & .012 \\
\hline$>50 \%$ & $174(82.1)$ & $66(78.6)$ & & \\
\hline $30 \%-50 \%$ & 38 (17.9) & $18(21.4)$ & & \\
\hline Unknown & 2 & 17 & & \\
\hline NYHA & & & & .007 \\
\hline Class I & 91 (42.9) & $21(25.6)$ & 37.1 & \\
\hline Class II & $78(36.8)$ & $37(45.1)$ & -17.0 & \\
\hline Class III & $34(16.0)$ & $19(23.2)$ & -18.0 & \\
\hline Class IV & $9(4.2)$ & $5(6.1)$ & -8.4 & \\
\hline Unknown & 2 & 19 & & \\
\hline Atrial fibrillation & $11(5.1)$ & $9(8.9)$ & -14.8 & .220 \\
\hline
\end{tabular}

$C T D$, Connective tissue disease; $S T J$, sinotubular junction; $L V E F$, left ventricular ejection fraction; NYHA, New York Heart Association. 
TABLE 2. Leaflet intervention in tricuspid and bicuspid aortic valves

\begin{tabular}{lcc}
\hline & $\begin{array}{c}\text { Tricuspid } \\
\text { aortic valve }\end{array}$ & $\begin{array}{c}\text { Bicuspid } \\
\text { aortic valve }\end{array}$ \\
\hline Leaflet intervention & $155(68.9)$ & $23(25.8)$ \\
$\quad$ None & $67(29.8)$ & $54(60.7)$ \\
Plication & $1(0.4)$ & $8(9.0)$ \\
Pericardial extension & $1(0.4)$ & $3(3.4)$ \\
Plication + pericardial & & \\
$\quad$ extension & 0 & $1(1.1)$ \\
Shaving & $1(0.4)$ & 0 \\
$\quad$ Plication + shaving & &
\end{tabular}

for the 2 procedures while also allowing for other variables. The aim of the Cox models was to allow for potential imbalances between the groups when comparing the reimplantation and remodeling procedures. We started by just allowing for differences between the reimplantation and remodeling procedures and then also included age, and then we looked at models including both the procedures, age, and one other variable.

The survival of patients in the study was compared with the predicted survival experience for equivalent members of the general population with respect to age and sex. The latter was determined with the German life-table, 2010/2012 (www.destatis.de). The subject-years method was used to compare the numbers of deaths for the 2 procedures with the expected (ie, average) numbers of deaths in the general population with the same age and sex profile. The standardized mortality ratio was calculated by the actual number of deaths divided by expected number of deaths based on the life-table.

\section{RESULTS}

\section{Clinical Characteristics}

Clinical characteristics are presented in Tables 3 and 4. Follow-up in the reimplantation group was $6.4 \pm 4.2$ years (range, $0-21.9$ years) and $10.1 \pm 5.6$ (range, $0-19.8$ years) in the remodeling group $(P<.001)$.

\section{Early Mortality}

There were 5 early deaths overall (Table 4). In the reimplantation group, the causes for early death were sudden cardiac death, cardiac arrest with hemorrhagic shock, and hypoxic brain injury and in the remodeling the causes were septic shock with multiorgan failure and cardiogenic shock.

\section{Late Mortality}

A total of 38 late deaths occurred during the study time (Table 4). There were 6 late cardiac deaths in the remodeling group ( 3 patients with sudden cardiac death, 1 patient with heart failure, 1 patient with cardiac arrest after suspected myocardial infarction, and 1 patient with cardiac decompensation after pulmonary embolism). In the remodeling group, 9 late cardiac deaths occurred (2 patients with myocardial infarction, 2 patients with heart failure, 2 patients with acute aortic dissection, 1 patient with sudden cardiac death, 1 patient with cardiac arrest after descending aorta replacement and multiple bleedings, and 1 patient with cardiac decompensation after systemic inflammatory response syndrome).

\section{Overall Mortality}

The Cox proportional hazards model revealed a hazard ratio (HR) remodeling/reimplantation of $1.68(95 \% \mathrm{CI}$, $0.89-3.19, P=.111$ ), indicating no significant evidence of a difference in survival times (Figure 1). When we adjusted for age and sex, the estimated HR remodeling/reimplantation was smaller (HR, 1.23; 95\% CI, 0.63-2.41, $P=.549$ ) and age was a significant risk factor for survival (HR per year: $1.04 ; 95 \% \mathrm{CI}, 1.02-1.07, P=.001$ ). In

TABLE 3. Operative details of the patients

\begin{tabular}{|c|c|c|c|}
\hline Parameter & Reimplantation $(n=214)$ & Remodeling $(\mathrm{n}=101)$ & $P$ value \\
\hline Elective surgery & $196(91.6)$ & $87(86.1)$ & .162 \\
\hline \multicolumn{4}{|l|}{ Additional procedures } \\
\hline Partial or total aortic arch replacement & $35(16.4)$ & $24(23.8)$ & .124 \\
\hline Mitral valve intervention & $8(3.7)$ & $7(6.9)$ & .258 \\
\hline CABG & $23(10.7)$ & $11(10.9)$ & 1 \\
\hline Aortic valve cusp intervention & $107(50.0)$ & $31(30.7)$ & .002 \\
\hline Size of prosthesis, $\mathrm{mm}$ & & & $<.001$ \\
\hline 24 & $1(0.5)$ & $5(5.0)$ & \\
\hline 26 & $8(3.7)$ & $14(13.9)$ & \\
\hline 28 & $43(20.1)$ & $38(37.6)$ & \\
\hline 30 & $123(57.5)$ & $38(37.6)$ & \\
\hline 32 & $39(18.2)$ & $6(5.9)$ & \\
\hline \multicolumn{4}{|l|}{ Surgical data } \\
\hline CPB time, $\min$ & $218.1 \pm 51.0$ & $177.1 \pm 47.1$ & $<.001$ \\
\hline Crossclamp time, min & $180.0 \pm 43.3$ & $134.5 \pm 43.9$ & $<.001$ \\
\hline \multicolumn{4}{|l|}{ Circulatory arrest } \\
\hline No. of patients & $52(24.3)$ & $51(50.5)$ & \\
\hline Circulatory arrest time, min & $29.4 \pm 23.3$ & $22.2 \pm 14.1$ & .022 \\
\hline
\end{tabular}

$C A B G$, Coronary artery bypass grafting; $C P B$, cardiopulmonary bypass. 
TABLE 4. Follow-up data

\begin{tabular}{|c|c|c|}
\hline Parameter & Reimplantation $(n=214)$ & Remodeling $(\mathrm{n}=101)$ \\
\hline Follow-up, y (mean $\pm \mathrm{SD}$ and range)* & $\begin{array}{c}6.4 \pm 4.2 \\
0-21.9\end{array}$ & $\begin{array}{c}10.1 \pm 5.6 \\
0-19.8\end{array}$ \\
\hline Mortality & $17(7.9)$ & $26(25.7)$ \\
\hline Early mortality $(\leq 30 \mathrm{~d})$ & $3(1.4)$ & $2(2.0)$ \\
\hline Late mortality $(>30 \mathrm{~d})$ & $14(6.5)$ & $24(23.8)$ \\
\hline \multicolumn{3}{|l|}{ Cause of death } \\
\hline Noncardiac & $7(50.0)$ & $11(45.8)$ \\
\hline Cardiac & $6(42.9)$ & $9(37.5)$ \\
\hline Unknown & $1(7.1)$ & $4(16.7)$ \\
\hline Aortic valve reoperation & $13(6.1)$ & $14(13.9)$ \\
\hline \multicolumn{3}{|l|}{ Aortic valve phenotype } \\
\hline $\mathrm{BAV}, \mathrm{n}$ & 7 & 4 \\
\hline $\mathrm{TAV}, \mathrm{n}$ & 6 & 10 \\
\hline \multicolumn{3}{|l|}{ Finding at reoperation } \\
\hline \multicolumn{3}{|c|}{ Leaflet degeneration (fibrotic shrinkage, calcification), $\mathrm{n}$} \\
\hline Total & 11 & 6 \\
\hline BAV & 7 & 3 \\
\hline TAV & 4 & 3 \\
\hline \multicolumn{3}{|l|}{ Annulus dilatation, $\mathrm{n}$} \\
\hline Total & 0 & 6 \\
\hline BAV & 0 & 1 \\
\hline TAV & 0 & 5 \\
\hline Endocarditis, $\mathrm{n}$ & TAV: 1 & TAV: 1 \\
\hline Unknown, $\mathrm{n}$ & TAV: 1 & TAV: 1 \\
\hline \multicolumn{3}{|l|}{ Hemodynamic indication for reoperation } \\
\hline Stenosis & 3 & 1 \\
\hline Insufficiency & 9 (1 endocarditis) & 11 ( 1 endocarditis) \\
\hline Combined & 1 & 2 \\
\hline Echocardiographic follow-up data, $\mathrm{n}^{*}$ & 104 & 61 \\
\hline Follow-up, y & $5.9 \pm 3.3$ & $10.1 \pm 4.4$ \\
\hline \multicolumn{3}{|l|}{ Aortic regurgitation } \\
\hline None/trace & $60(57.7)$ & $23(37.7)$ \\
\hline Mild & $37(35.6)$ & $29(47.5)$ \\
\hline Moderate & $6(5.8)$ & $8(13.1)$ \\
\hline Severe & $1(1.0)$ & $1(1.6)$ \\
\hline Mean pressure gradient, $\mathrm{mm} \mathrm{Hg}$ & $6.5 \pm 4.1$ & $6.0 \pm 3.4$ \\
\hline
\end{tabular}

$B A V$, Bicuspid aortic valve; $T A V$, tricuspid aortic valve. *Only patients with echocardiographic follow-up $>1$ year.

addition, including other imbalances between groups (Table 1) in the multivariate Cox model did not reveal a difference in survival between the groups.

Survival was comparable with the normal population in the reimplantation group (standardized mortality ratio: $1.26 \pm 0.60, P=.39$ ) but was lower in the remodeling group (standardized mortality ratio: $1.64 \pm 0.63, P=.047$ ).

A multivariable Cox proportional hazards model using backward elimination including the variables listed in Table 1 revealed age (HR, $1.03 ; 95 \%$ CI, 1.01-1.06, $P=.02$ ), diabetes (HR, 3.04; 95\% CI, 1.06-8.73, $P=.039)$, and greater New York Heart Association classification (HR per increment 1.48; 95\% CI, 1.04-2.12, $P=.032)$ as risk factors for shorter survival time. There was not significant evidence of a difference in survival time between TAV and BAV patients $(P=.095$, Figure E2).
A total of $2(4.3 \%)$ patients with connective tissue disease (CTD) died compared with $41(15.3 \%)$ patients in the non-CTD group. In the remodeling group, $2(15.5 \%)$ patients with annuloplasty and $24(28.2 \%)$ patients without annuloplasty died.

\section{Reoperation}

There was no statistically significant difference regarding reoperation in both groups ( $P=.65$, Figure 2$)$. The cumulative incidence of reoperation at 10 years was $5.8 \%(95 \%$ CI, 2.8-12.0) for the reimplantation group and $11.7 \%(95 \%$ CI, 6.5-20.7) for the remodeling group. A total of $27 \mathrm{pa}-$ tients (BAV: $\mathrm{n}=11$; TAV: $\mathrm{n}=16$ ) needed a reoperation. The cumulative incidence of reoperation at 10 and 16 years was $5.3 \%(95 \% \mathrm{CI}, 1.7-15.4)$ and $48.4 \%$ (95\% CI, 27.7-74.1) in BAV patients and 9.8\% (95\% CI, 


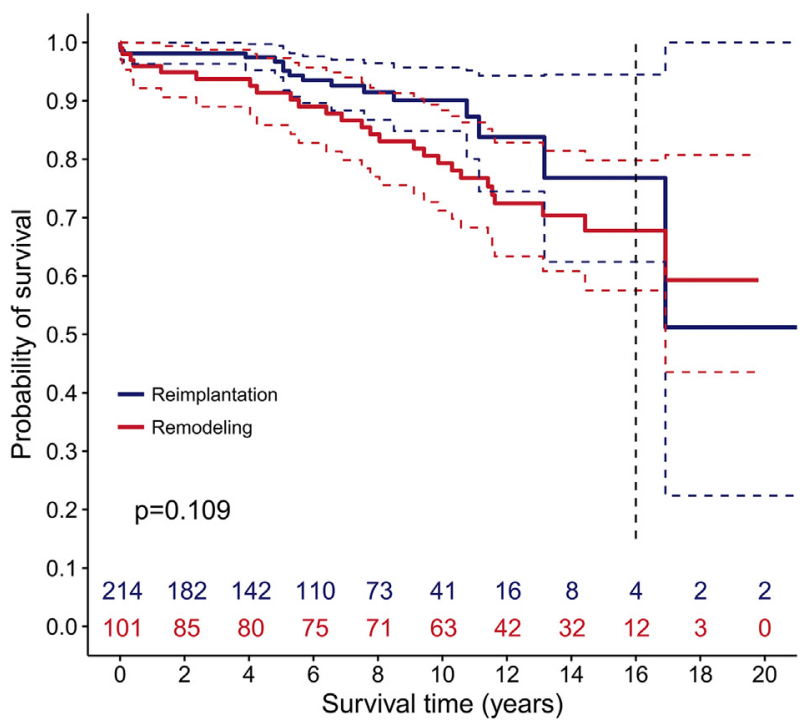

FIGURE 1. Kaplan-Meier survival curve for reimplantation and remodeling technique. The dashed line at 16 years represents the threshold of a statistical meaningful sample size.

5.9-16.0) and $10.9 \%$ (95\% CI, 6.6-17.5) for TAV patients, respectively $(P=.13)$ (Figure 3$)$. The landmark analysis showed that the difference regarding reoperation between the BAV and TAV patients was only significant considering patients living longer than 10 years $(P<.001)$ (Figure 3$)$. Causes for reoperation were different (Table 4). Five $(10.6 \%)$ reoperations had to be performed in patients with CTD compared with $22(8.2 \%)$ patients without CTD. A total of $7 \mathrm{BAV}$ patients and 2 patients with Marfan syndrome needed reoperation in the reimplantation group and $4 \mathrm{BAV}$ patients and 3 patients with Marfan syndrome in the remodeling group. A total of 10 of 11 reoperated BAV patients developed fibrotic tissue shrinkage or calcification of the leaflets causing predominantly aortic insufficiency with a lesser degree of stenosis. In the remodeling group, 3 $(18.8 \%)$ patients with annuloplasty were reoperated and $11(12.9 \%)$ patients without annuloplasty. Two patients were reoperated due to aortic valve endocarditis.

\section{Morbidity}

A stroke occurred in $8(3.7 \%)$ patients of the reimplantation group and $2(2.0 \%)$ patients in the remodeling group. Major bleeding events were reported by $10(4.7 \%)$ patients in the reimplantation group and $4(4.0 \%)$ patients in the remodeling group. Two $(0.9 \%)$ in the reimplantation group and $2(2.0 \%)$ patients in the remodeling group reported noncerebral embolic events.

\section{DISCUSSION}

In this retrospective study, we found that the survival and cumulative incidence of reoperation after the remodeling and reimplantation aortic valve-sparing root replacement techniques did not differ significantly. The same holds true for the probability of survival in TAV and BAV patients. However, more reoperations were necessary in BAV patients in the second decade after the reoperation, especially in the reimplantation group.

Normal anatomy warrants optimal function. Keeping this maxim in mind, the restoration of normal anatomy in general is appealing if the tissue is of favorable quality to expect

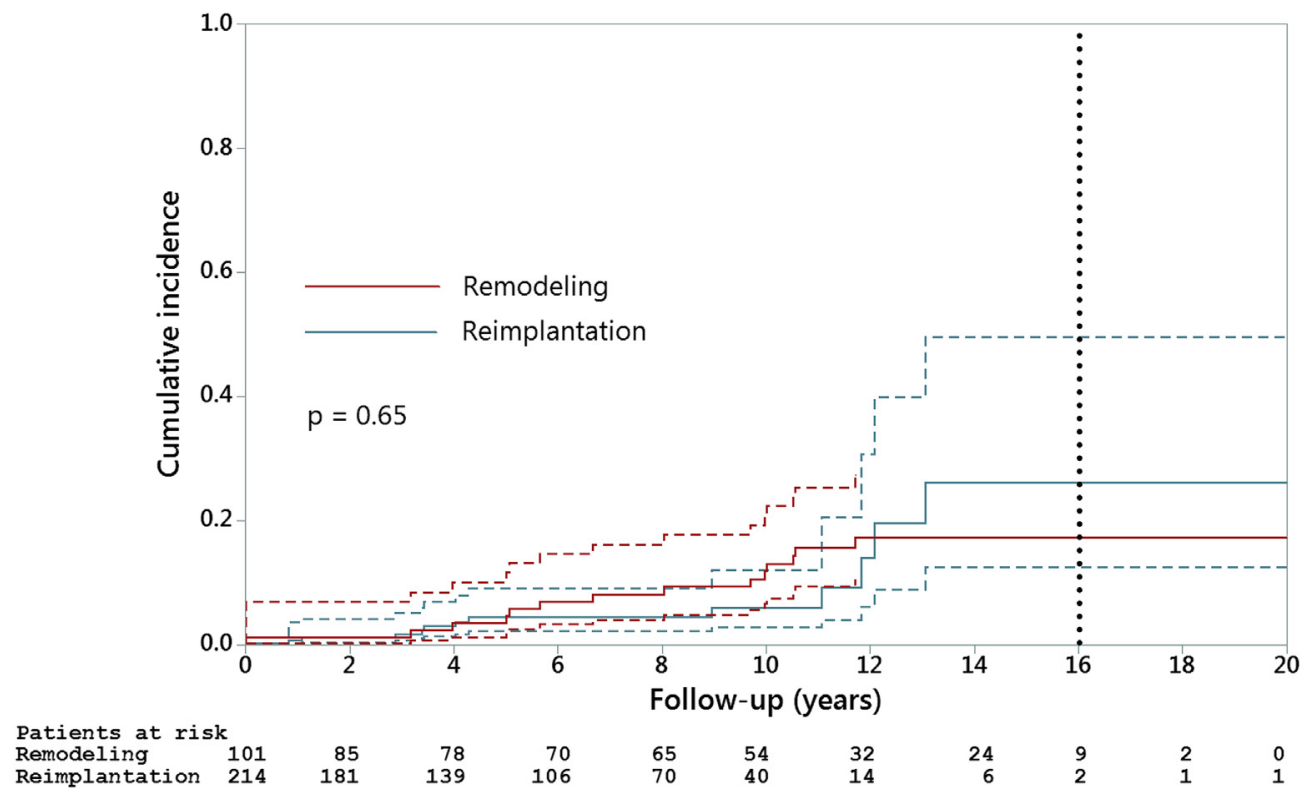

FIGURE 2. Cumulative incidence of reoperation for reimplantation and remodeling technique. The dotted line at 16 years represents the threshold of a statistical meaningful sample size. 

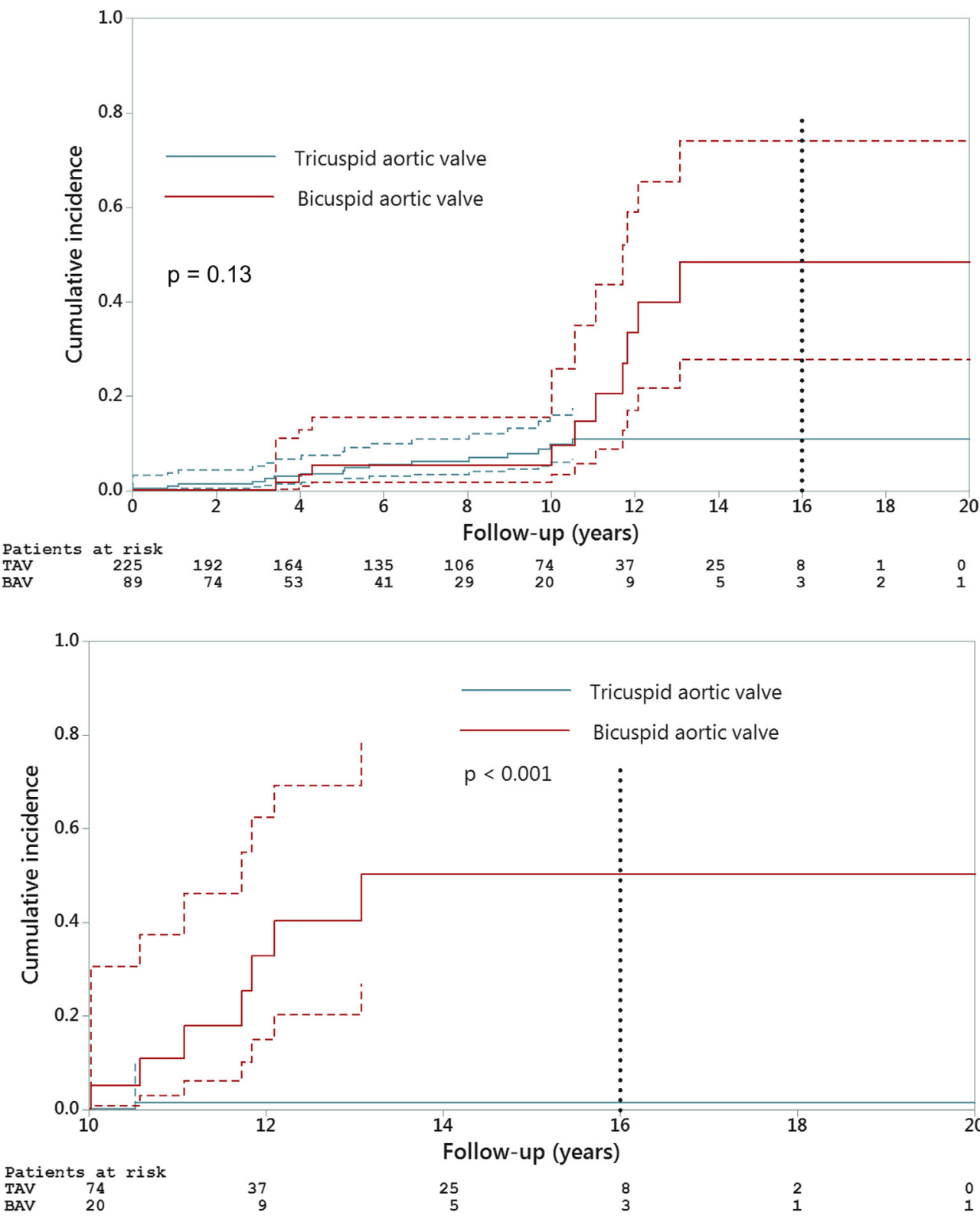

FIGURE 3. Top: Cumulative incidence of reoperation for all BAV and TAV patients. Bottom: Landmark analysis: cumulative incidence of reoperation for $\mathrm{BAV}$ and TAV patients in 10-year survivors. The dotted lines at 16 years represent the threshold of a statistical meaningful sample size.

long-term function and durability. This is particularly important for the aortic valve, which plays a crucial role for left-ventricular to aortic coupling, allowing for passage of blood at rest and exercise with low energy loss. ${ }^{16}$ To achieve this goal, the aortic valve performs complex movements. It follows sophisticated 3-dimensional deformational dynamics, thereby reducing stress on the aortic cusps, minimizing transvalvular energy loss, and optimizing coronary flow. ${ }^{17-19}$

Preserving the aortic leaflets and restoring physiological root dynamics theoretically bear the potential to favorably influence long-term outcome of patients. The remodeling technique includes the resection of the sinuses only and does not touch the interleaflet trigones and the annulus of the aortic valve, which seems to restore some kind of distensibility in this area in contrast the reimplantation technique, which incorporates the aortic valve into a rigid Dacron tube including the annulus of the aortic valve. ${ }^{3,4}$ This technique, however, corrects and prevents annulus dilatation and as such may also prevent the development of aortic regurgitation in the long term; therefore, we have preferred this technique in recent years.

As one of the major determinants of treatment, quality survival after valve-sparing aortic root replacement was 
excellent, being $72.6 \% \quad(95 \%$ CI, $0.64-0.81)$ after 15 years, which is comparable with the normal population and the data of other groups. ${ }^{20-26}$ Reasons for this favorable outcome are not only the physiological concept of valve sparing but also the close follow-up of these patients. Survival in the reimplantation group was comparable with the normal population, and we found no difference in survival between the remodeling and the reimplantation groups. However, survival was lower than normal in the remodeling group. Whether this is related to the small number of patients, the lower ejection fraction and greater New York Heart Association classification, or the older age at the primary operation remains to be evaluated further.

The rate of reoperation was acceptable until 10 years postoperatively, as also reported by other groups, ${ }^{20,24,27}$ but thereafter we observed an obvious increase in the rate of reoperation especially in BAV patients compared with TAV patients, as shown by the landmark analysis. It must be considered, however, that the number of patients is relatively small and needs further evaluation with larger numbers of patients. Thus, our results are less favorable compared with those reported for the remodeling technique and BAV patients by Schneider and colleagues, ${ }^{27}$ with a cumulative incidence of reoperation of $21.7 \%$ at 15 years. It is possible that in general our repair techniques in BAV patients were insufficient, although 10 of all reoperated BAV patients left the operating theater at primary repair with no aortic regurgitation and 1 patient with trivial aortic regurgitation. Furthermore, at primary operation, 10 of the 11 reoperated BAV patients had pliable leaflets, all were BAV type 1 left/right, and only in one a small calcification was present at the commissural remnant between the fused left and right coronary cusp, which was removed. In 5 patients, a plication of the leaflets was required, and in 6 patients none required additional cusp intervention. We found no systematic technical issue in our reoperated patients demonstrating that our kind of repair would lead to later fibrotic tissue changes and calcification (10 of 11). Whether more coaptation area by using pericardial leaflet augmentation ${ }^{28}$ leads to better results remains speculative in as much as the use of pericardium for cusp repair was reported to be a risk factor for earlier reoperation. ${ }^{25}$ More innovative repair techniques with greater coaptation area, avoidance of symmetrical prolapse, and more experience might result in better outcomes as reported by Schneider and colleagues,${ }^{27}$ with roughly $20 \%$ cumulative incidence of reoperation after 12 years. Furthermore, circumferential annuloplasty as described by Lansac and colleagues ${ }^{29}$ or Schneider and colleagues ${ }^{27}$ may function as an additional protective effect against aortic insufficiency and as such improve the outcome. Whether the observed degenerative process is related to a genetic background or whether the unphysiological morphology and hemodynamics in patients with a BAV are causative remains unknown.

Another aspect that could have some influence on leaflet degeneration is the lack of sinuses in the reimplantation group, especially for BAV, leading to malrotation of the vortex behind the leaflets as recently shown by Oechtering and colleagues. ${ }^{30}$ This degenerative process obviously accelerates in the second decade after surgery. These lessoptimal results prompted us to rethink BAV for valvesparing root replacement and in general may require a lot of more clinical and experimental research to shed light in this less-favorable issue. In view of these data, we more clearly inform our patients on the increased probability of reoperation in the second decade especially after BAV repair, confine the indication to absolute pliable leaflet tissue, perform more radical triangular resection of the thickened raphe with pericardial replacement extending on the free leaflet edges (right and left coronary cusps) to get more pliability and to increase coaptation area, and do not use cusps for repair that show any signs of beginning calcification. Together, this means some restriction in BAV indication. A Bio-Bentall procedure may be an alternative in those patients who do not like to take anticoagulation or a regular Bentall prosthesis with a mechanical valve. Nevertheless, the results with valve-sparing root repair are at least equivalent with a lower rate of composite events. $^{31,32}$

\section{Limitations of the Study}

This is a retrospective analysis and as such has a lot of flaws, weakening the comparability of the different groups. Nevertheless, it is a clinical series with relatively long follow-up time, providing us with some view on the results in the second decade. The number of patients is small, especially in the second decade; however, the number of events (late death and reoperation) is around $10 \%$ of the total cohort, and there is a clear trend for earlier degeneration in BAV compared with TAV, supporting the theoretical background of BAV as a less physiological valve. Because the follow-up time of the reimplantation procedure was shorter than for the remodeling group, it may explain the better survival compared with normal; however, this must be evaluated further.

In the early years, we did not use transesophageal echocardiography for analysis of intraoperative root dimensions and aortic valve function and defined the valve competent when the root was pressurized after removal of the aortic clamp and no dilatation of the left ventricle occurred. Since 2003, we have used intraoperative transesophageal echocardiography, which has allowed us to gain more qualitative data. However, in most patients, a transthoracic echocardiogram was performed predischarge, providing some information on the valve function. Furthermore, many patients had no records of aortic valve function and dimensions. 
It is possible that there are certain, unknown patients with significant valve lesion needing reoperation because of the incomplete echocardiographic late follow-up. Whether those shortcomings influence results remains speculative in as much as almost all reoperated BAV patients showed fibrous and calcifications of the leaflets at reoperation, which is most likely an intrinsic process of the tissue of the leaflets.

\section{CONCLUSIONS}

In this series, survival was near normal in both the remodeling and reimplantation aortic valve-sparing root replacement techniques, and the cumulative risk of reoperation remained stable up to 10 years postoperatively. In the second decade, we observed an increase in reoperations, particularly in BAV patients. Although the number of BAV patients in the second decade is small, our findings caused us to closely rethink our indication and technique for BAV valve-sparing root replacement.

\section{Conflict of Interest Statement}

Authors have nothing to disclose with regard to commercial support.

The authors are thankful to Dr Derek Robinson for his support regarding the statistical analyses.

\section{References}

1. Yacoub MH. Results of valve conserving operations for aortic regurgitation. Circulation. 1983;68:311-2.

2. David TE, Feindel CM. An aortic valve-sparing operation for patients with aortic incompetence and aneurysm of the ascending aorta. J Thorac Cardiovasc Surg. 1992;103:617-21.

3. Leyh RG, Schmidtke C, Sievers HH, Yacoub MH. Opening and closing characteristics of the aortic valve after different types of valve-preserving surgery. Circulation. 1999;100:2153-60.

4. Erasmi A, Sievers HH, Scharfschwerdt M, Eckel T, Misfeld M. In vitro hydrodynamics, cusp-bending deformation, and root distensibility for different types of aortic valve-sparing operations: remodeling, sinus prosthesis, and reimplantation. J Thorac Cardiovasc Surg. 2005;130:1044-9.

5. Miller DC. Valve-sparing aortic root replacement in patients with the Marfan syndrome. J Thorac Cardiovasc Surg. 2003;125:773-8.

6. De Paulis R, De Matteis GM, Nardi P, Scaffa R, Bassano C, Chiariello L. Analysis of valve motion after the reimplantation type of valve-sparing procedure (David I) with a new aortic root conduit. Ann Thorac Surg. 2002;74:53-7.

7. David TE, Armstrong S, Manlhiot C, McCrindle BW, Feindel CM. Long-term results of aortic root repair using the reimplantation technique. J Thorac Cardiovasc Surg. 2013;145:S22-5

8. Coselli JS, Volguina IV, LeMaire SA, Sundt TM, Connolly HM, Stephens EH, et al. Early and 1-year outcomes of aortic root surgery in patients with Marfan syndrome: a prospective, multicenter, comparative study. J Thorac Cardiovasc Surg. 2014;147:1758-66. 1767.e1-4.

9. Shrestha M, Baraki H, Maeding I, Fitzner S, Sarikouch S, Khaladj N, et al. Longterm results after aortic valve-sparing operation (David I). Eur J Cardiothorac Surg. 2012;41:56-61.

10. Miller DC. Valve-sparing aortic root replacement: current state of the art and where are we headed? Ann Thorac Surg. 2007;83:S736-9.

11. Clark TG, Altman DG, De Stavola BL. Quantification of the completeness of follow-up. Lancet. 2002;359:1309-10.
12. David TE, Feindel CM, Bos J. Repair of the aortic valve in patients with aortic insufficiency and aortic root aneurysm. J Thorac Cardiovasc Surg. 1995;109: $345-51$

13. Hanke T, Charitos EI, Stierle U, Robinson D, Gorski A, Sievers HH, et al. Factors associated with the development of aortic valve regurgitation over time after two different techniques of valve-sparing aortic root surgery. J Thorac Cardiovasc Surg. 2009; 137:314-9.

14. Austin PC. Using the standardized difference to compare the prevalence of a binary variable between two groups in observational research. Commun Stat Simul Comput. 2009;38:1228-34.

15. Benjamini Y, Hochberg Y. Controlling the false discovery rate: a practical and powerful approach to multiple testing. J Royal Stat Soc Ser B. 1995;57: 289-300.

16. Yacoub MH, Kilner PJ, Birks EJ, Misfeld M. The aortic outflow and root: a tale of dynamism and crosstalk. Ann Thorac Surg. 1999;68:S37-43.

17. Dagum P, Green GR, Nistal FJ, Daughters GT, Timek TA, Foppiano LE, et al Deformational dynamics of the aortic root: modes and physiologic determinants Circulation. 1999;100:II54-62.

18. Bellhouse BJ, Bellhouse FH, Reid KG. Fluid mechanics of the aortic root with application to coronary flow. Nature. 1968;219:1059-61.

19. Davies JE, Parker KH, Francis DP, Hughes AD, Mayet J. What is the role of the aorta in directing coronary blood flow? Heart. 2008;94 $1545-7$.

20. David TE, David CM, Feindel CM, Manlhiot C. Reimplantation of the aortic valve at 20 years. J Thorac Cardiovasc Surg. 2017; 153:232-8.

21. Richardt D, Stierle U, Sievers HH. Long-term results after aortic valve-sparingreimplantation operation (David) in bicuspid aortic valve. J Heart Valve Dis 2015;24:4-9.

22. Aicher D, Langer F, Lausberg H, Bierbach B, Schafers HJ. Aortic root remodeling: ten-year experience with 274 patients. J Thorac Cardiovasc Surg. 2007;134 909-15.

23. Malvindi PG, Cappai A, Basciu A, Raffa GM, Barbone A, Citterio E, et al. David operation: single center 10-year experience. J Cardiovasc Surg (Torino). 2015; 56:639-45.

24. Kari FA, Doll KN, Hemmer W, Liebrich M, Sievers HH, Richardt D, et al. Survival and freedom from aortic valve-related reoperation after valve-sparing aortic root replacement in 1015 patients. Interact Cardiovasc Thorac Surg. 2016;22: 431-8.

25. Schäfers HJ, Raddatz A, Schmied W, Takahashi H, Miura Y, Kunihara T, et al Reexamining remodeling. J Thorac Cardiovasc Surg. 2015;149:S30-6.

26. Kvitting JP, Kari FA, Fischbein MP, Liang DH, Beraud AS, Stephens EH, et al David valve-sparing aortic root replacement: equivalent mid-term outcome for different valve types with or without connective tissue disorder. J Thorac Cardiovasc Surg. 2013;145:117-26. 127.e1-5.

27. Schneider U, Feldner SK, Hofmann C, Schope J, Wagenpfeil S, Giebels C, et al Two decades of experience with root remodeling and valve repair for bicuspid aortic valves. J Thorac Cardiovasc Surg. 2017;153:S65-71.

28. Thudt M, Papadopoulos N, Monsefi N, Miskovic A, Karimian-Tabrizi A, Zierer A, et al. Long-term results following pericardial patch augmentation for incompetent bicuspid aortic valves: a single center experience. Ann Thorac Surg. 2017; 103:1186-92.

29. Lansac E, Di Centa I, Sleilaty G, Lejeune S, Berrebi A, Zacek P, et al. Remodel ing root repair with an external aortic ring annuloplasty. J Thorac Cardiovasc Surg. 2017; 153:1033-42.

30. Oechtering TH, Frydrychowicz A, Sievers HH. Malrotated sinus vortices in straight graft valve-sparing aortic root treatment: a matter of concern? J Thorac Cardiovasc Surg. 2017;154:794-7.

31. Vallabhajosyula P, Szeto WY, Habertheuer A, Komlo C, Milewski RK, McCarthy F, et al. Bicuspid aortic insufficiency with aortic root aneurysm: root reimplantation versus bentall root replacement. Ann Thorac Surg. 2016; 102:1221-8

32. Price J, Magruder JT, Young A, Grimm JC, Patel ND, Alejo D, et al. Long-term outcomes of aortic root operations for Marfan syndrome: a comparison of Bentall versus aortic valve-sparing procedures. J Thorac Cardiovasc Surg. 2016;151: 330-6.

Key Words: valve-sparing root replacement, remodeling, reimplantation, bicuspid aortic valve, long-term results 


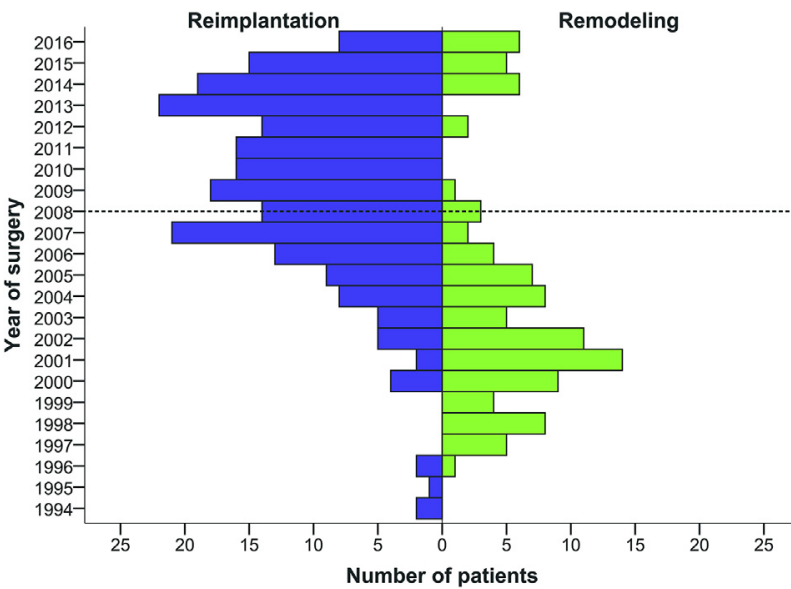

FIGURE E1. Histogram showing the annual numbers of the 2 operative techniques over time. The dotted line represents the time point when a change in our operative policy took place (see Materials and Methods section).

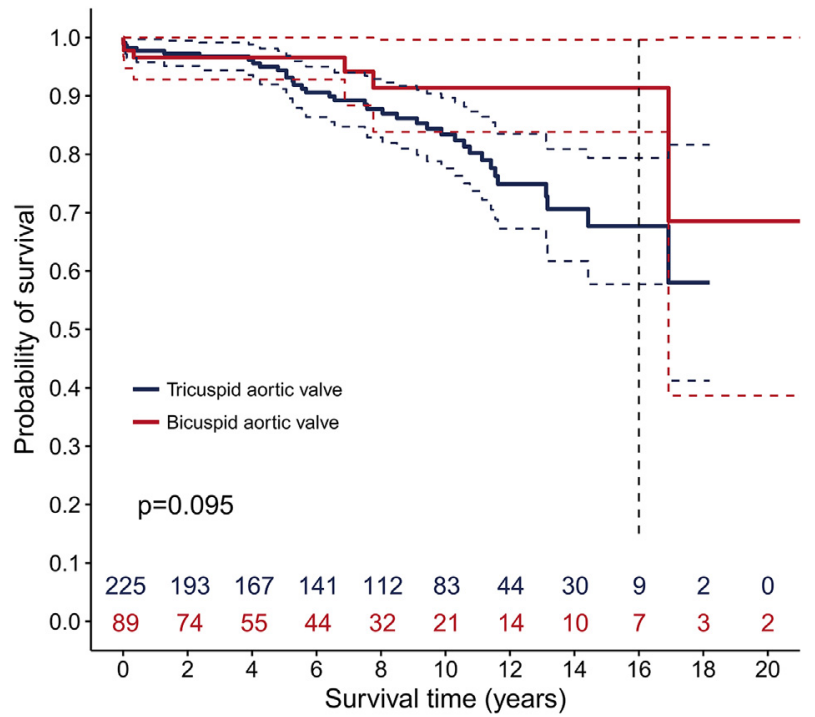

FIGURE E2. Kaplan-Meier survival curve for BAV and TAV patients. The dashed line at 16 years represents the threshold of a statistical meaningful sample size. Age at operation of TAV patients was $54.0 \pm 14.8$ years and that of BAV patients $44.0 \pm 12.2$ years. 